\title{
Design and Application of an Evaluation Index System for Urban Development Quality of China's Sub-provincial Cities in the New Era
}

\author{
Shanhui Wang ${ }^{1}$, Xiaoli $\mathrm{Lu}^{2 *}$ \\ ${ }^{1}$ Ningbo Institute of technology, Zhejiang University, Ningbo 315100, China \\ ${ }^{2}$ Zhejiang Pharmaceutical College, Ningbo 315100, China
}

Corresponding Author Email: luxl@ mail.zjpc.net.cn

https://doi.org/10.18280/ijsdp.150309

Received: 25 October 2019

Accepted: 3 January 2020

\section{Keywords:}

urban development quality, evaluation index system, analytic hierarchy process (AHP), weighted sum model (WSM), subprovincial cities

\begin{abstract}
China has entered a new era of development. In the new era, the quality of urban development is endowed with new connotations. Through in-depth analysis on these connotations, this paper sets up a $1+2+3+4+5+6$ logical framework and then establishes an evaluation index system for urban development quality in the new era. After that, the analytic hierarchy process (AHP) and weighted sum model (WSM) were introduced to evaluate the development quality of the 15 sub-provincial cities in China, based on the statistics released by the state and the cities in 2017. The results show obvious regional differences in the quality of urban development. In general, the cities in the eastern region are more developed than those in the central and western regions, and the cities in the southern region are more developed than those in the northern region. The cities in developed areas boast relatively high development quality, because city clusters are relatively mature in these areas. Besides, large cities are not necessarily better developed, i.e. there is no absolutely positive correlation between city size and development quality. In addition, there are marked differences between the sub-provincial cities in culture and urban management. To realize high-quality development, a city must strike a balance between multiple aspects, such as economy, society, ecology, public service and urban management, according to their own features. The research results shed important new light on urban development in the new era.
\end{abstract}

\section{INTRODUCTION}

Currently, China is undergoing an economic shift from speed of growth to quality of growth, and striving to promote economic quality. The current growth pattern of China has many imbalances and inadequacies, calling for a high-quality and effective pattern of growth that truly satisfies the growing economic, political, cultural, social and ecological needs of the Chinese people. In 2018, the Chinese government set the national agenda for high-quality growth of economy at the Central Economic Work Conference. The agenda covers multiple aspects of high-quality growth, including but not limited to indicators, policies, standards, statistics, and performance. The key to high-quality growth lies in urban development. The quality of urban development can be measured by numerous indices, such as greenness, low-carbon capacity, subjective well-being, satisfaction of rational needs, and the harmony between man and nature. As China enters a new era, it is important to set up a scientific system of objective indices that accurately reflects the quality of urban development, and apply the system to evaluate and predict the current and future development quality of Chinese cities.

\section{LITERATURE REVIEW}

So far, the quality of urban development has mainly been evaluated by the composite index method. However, different indices are selected by scholars at home and abroad, failing to form a unified system of evaluation indices. Inaei Yukio, a Japanese urbanist, was the first to design an index system for urban development quality, which involves such five indices as scale, location, employment, economic activities, and population growth [1].

Being a highly inclusive and evolving concept, the quality of urban development is difficult to be clearly defined. Many scholars have attempted to design a complete index system from a particular perspective, which relates to their own research fields. As stakeholders with different demands for urban development, the scholars focus on different issues during the evaluation of urban development quality. As a result, the index systems designed by them emphasize on different aspects. Based on the emphases, the existing index systems for urban development quality fall into three categories: sustainability-based index systems, modernization-based index systems and competitivenessbased index systems.

(1) Sustainability-based index systems

In 2001, United Nations Centre for Human Settlements (UNCHS-Habitat) proposed a sustainability-based index system, which consists of 12 indices in 5 categories: production capacity, infrastructure, waste treatment, health, and education. In 2004, UNCHS-Habitat [2, 3] established another two index systems, namely, the City Development Index (CDI) and the Urban Indicators Guideline (UIG). Many researches evaluate city sustainability from the perspective of 
economic, social and environmental subsystems [4-11].

(2) Modernization-based index systems

In 1960, more than 30 experts from Japan and the US designed the Hakone model, a standard for the development quality of modern cities, drawing on the features of modernization. Focusing on the urbanization process, British geographer Cloke [12] developed an index system for urbanization, including living conditions, the distance to city center and 14 other indices. From the angles of planning, facilities, management and construction fund, Yang and Chen [13] created and applied an index system for evaluating urban modernization. To evaluate urbanization quality, Ye [14] constructed an index system covering urban modernization and urban-rural integration.

(3) Competitiveness-based index systems

The competitiveness-based index systems are either explanatory or exhibitory. The explanatory index systems generally qualify urban competitiveness based on the relationship between influencing factors. Most of these systems are inspired by the national competitiveness theory of Porter [15]. For example, Michael E. Porter proposed the diamond model, which highlights the interaction between various factors, to evaluate urban competitiveness from six aspects, namely, production factors and demand conditions. Meanwhile, the exhibitory index systems quantify urban competitiveness by integrating the factors affecting urban economy and society. For instance, Rondinelli [16] designed such an index system through data collection and analysis. A few scholars combined the merits of the two types of index systems. For instance, Peter and Balwant stressed on the correlation between economy and strategy in the explanatory framework, and described urban competitiveness as a threefactor function in the exhibitory framework [17].

The most authoritative and influential competitivenessbased index system is undoubtedly the international competitiveness evaluation system, which was jointly developed by the World Economic Forum (WEF) and the International Institute for Management Development (IMD) [18]. The evaluation system comprises of more than 300 indices in four aspects (i.e. economic performance, government efficiency, enterprise efficiency and infrastructure), following the eight-element theory for the evaluation of international competitiveness (i.e. domestic economic strength, nationalization level, financial environment, government role, infrastructure, enterprise management, scientific research and development and citizens quality). $\mathrm{Ni}$ [19] defined urban competitiveness as the abilities of a city to create values and benefit its residents by edging out other cities in the competition for resources and market shares, and illustrated urban competitiveness by the bow-string-arrow model, creating a system of 6 exhibitory indices and 83 explanatory indices $[20,21]$.

The sheer number of cities around the world, coupled with their huge difference in development, makes it difficult to evaluate their development quality with the same index system. Therefore, most index systems for cities focus on one aspect of urban development, namely, economy, information and livability. As mentioned before, the quality of urban development is usually evaluated by composite index method. By this method, multiple indices are selected to form a comprehensive system that attaches equal importance to the quantity growth and quality improvement of cities. Such a system could measure the urban development quality in a country or region in an all-round way.
To establish a composite index system, the weight of each index is mainly determined by factor analysis, the Delphi method, the analytic hierarchy analysis (AHP), and the entropy weight method. Specifically, the factor analysis assesses the overall development of the target cities, and examines the main factors that affect the urban development. This approach may overlook or downplay the roles of key factors (e.g. social security and eco-environment) in urban development quality. The Delphi method and the AHP rely on experts to sort the importance of indices, and assign a weight to each index. Based on the degree of dispersion, the entropy weight method computes the entropy weight of each index by information entropy, and thus obtains the weight of the index system. But this method only applies to a small sample size.

Drawing on the above results, this paper aims to correctly evaluate the urban development quality of sub-provincial cities in China in the new era. Sub-provincial city is a prefecture-level city that is ruled by a province, but is administered independently in regard to economy and law. The evaluation indices were selected from six dimensions, namely, economy, society, ecology, culture, public service and urban management, and weighted by the AHP and weighted sum model (WSM). This research enriches the results on development quality, and provides reference to scientific quantification of urban development quality.

\section{PRELIMINARIES}

\subsection{Urban development quality in the new era}

As its name suggests, urban development quality covers two aspects: urban development and quality. Urban development refers to the economic growth and spatial evolution of a region realized through effective allocation of resources and through the massive gatherings of population, economic activities and commercial transactions, in an attempt to satisfy the human needs on different levels. For the long-term, sustainable survival of humans, urban development should improve every aspect of the city, and fully optimize the living quality, natural environment and cultural environment. The fundamental goal of a city is to provide sufficient material and spiritual wealth in a wide region and ensure the health and sustainability of the society, in addition to giving safe, reliable and lasting supports to the life and production of its dwellers.

In terms of quality, our society, which used to emphasize on the supply quantity of private and public goods, now attaches great importance to the quality of goods, and strives to strike a balance between quantity and quality. As defined by the International Organization for Standardization (ISO), quality is the sum of the attributes that reflect the capacity of an entity to meet explicit and implicit needs. Ishikawa [22] held that the true attributes of quality should satisfy the demand of consumers; note that the attributes refer to the properties unique to the entity.

Therefore, urban development quality should cover all dimensions of urban development, rather than focus on a single dimension. The typical dimensions include economy, society, ecology, culture, public service and urban management. The ultimate goal of urban development is to realize the all-round growth of humans. The needs of urban residents should be fulfilled timely through urban construction. The quality of urban development, as the result of urbanization at a certain time point, reflects the strengths and defects of 
urbanization, shedding light on how to promote the sustainability of urban development.

In the new era, the development of Chinese cities should meet the following requirements:

(1) Sustainability

Since the reform and opening-up, China has far surpassed any other economy in average annual rate of economic growth. The economic boom is accompanied by drastic changes in the connotations of urban development quality. Over the past 40 years, the focus of urban development has gradually shifted from economic quality to living quality to sustainability, as the material-centric philosophy of development is replaced by the thoughts of social development and sustainable development.

In the new era, the urban development should be sustainable, creating a favorable urban environment for work and life. In addition to normal functions, the cities must continuously improve economy, society and living conditions, and enhance the harmony between economy, society and environment, leaving sufficient room for future growth.

(2) Comprehensiveness

In the new era, urban development should pursue the overall benefits of economy, society and environment. In the course of quality development, the advantages of speed and efficiency should be transformed to superior quality. The one-sided emphasis on economic growth must be replaced with the pursuit of balanced development between economy and society, making the cities more attractive in terms of economy, happiness, culture and ecology.

\section{(3) Equity}

Soaring economy and surging population are two defining features of urbanization. The laborers migrating into cities could no longer make a living as they used to in rural areas. Facing intense competition, these laborers might lose their jobs due for multiple reasons (e.g. disability and aging). Hence, the urban development in the new era should pacify the social conflicts and promote social equity.

\section{(4) Coordination}

Coordination is an inherent feature of sustainable development. The growth pattern of China is not yet well coordinated. There are still prominent problems like regional imbalance, urban-rural gap, and irrational industrial structure, to name but a few. In the new era, urban development must strive to coordinate the growths between economy, society, ecology, culture and public service.

\section{(5) Synergy}

The Chinese government eyes synergistic development between large, medium and small cities through the construction of city clusters. The large cities, as innovation hubs and economic engines, are leaders of the synergistic development, which is essential to the high-quality development of the entire country. Therefore, the urban development in the new era must be synergistic.

\subsection{Logical framework}

In the new era, urban development is critical to the construction of a moderately well-off society in an all-round way. Focusing on economic and social aspects, the cities must improve the quality and benefits of development by implementing innovation, coordination, greening, opening-up and sharing, with supports from ecology, culture, public service and urban management. The urban development should be scientific, coordinated and sustainable, and provide guarantee to the return on investment, marketability of products, profit of enterprises, income of employees, tax of governments, and improvement of environment. On this basis, the logical framework for the evaluation of urban development quality was constructed (Figure 1).

As shown in Figure 1, the established logical framework has one center, two keys, three principles, four supports, five tools, and six features, and was thus named a $1+2+3+4+5+6$ framework. The one center refers to improving the quality and benefits of development, i.e. the key task and essence of urban development in the new era.

The two keys stand for economy and society. Economic growth provides the material support to urban development, while social progress ensures the order of urban growth. The quality and benefits of economic and social advancements are reflected by the output of many high-quality products from a few productive factors, which brings a good profit and better living conditions.

The three principles are scientific development, coordinated development and sustainable development, which respectively follow the law of economy, the law of society, and the law of nature.

In addition, the four supports include ecology, culture, public service and urban management. The five tools are innovation, coordination, greening, opening-up, and sharing. The six features are the return on investment, marketability of products, profit of enterprises, income of employees, tax of governments, and improvement of environment.

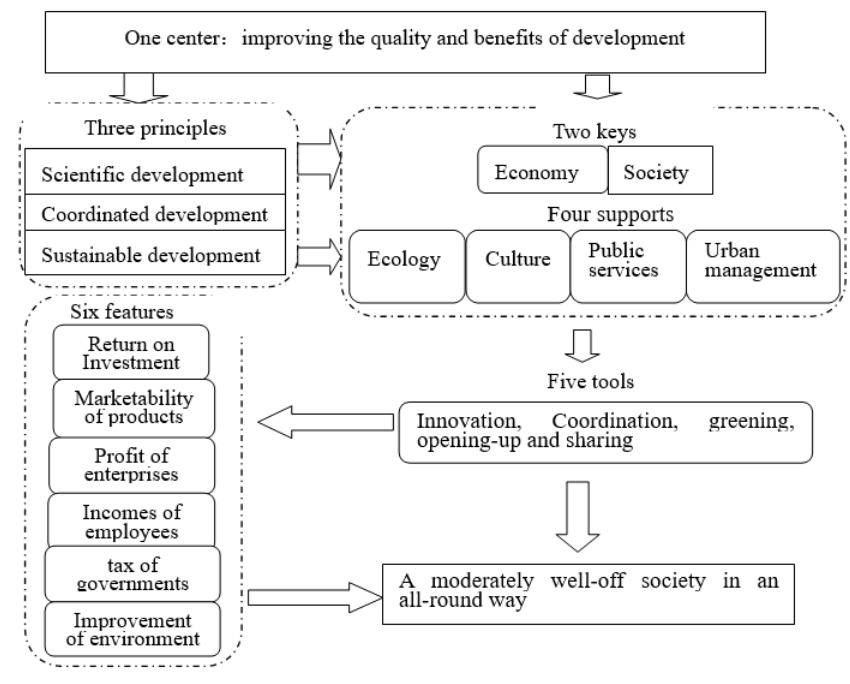

Figure 1. The logical framework for the evaluation of urban development quality in the new era

\section{METHODOLOGY}

\subsection{Evaluation index system}

Under the $1+2+3+4+5+6$ framework, a number of indices (Table 1) were selected from the aspects of economy, society, ecology, culture, public service and urban management, and synthesized into an evaluation index system for urban development quality of sub-provincial cities in China. 
Table 1. The established evaluation index system

\begin{tabular}{|c|c|c|c|c|}
\hline Goal & Criteria & & $\begin{array}{c}\text { Alternatives } \\
\end{array}$ & Direction \\
\hline \multirow{42}{*}{$\begin{array}{c}\text { Urban } \\
\text { development } \\
\text { quality } \\
\text { (A) }\end{array}$} & \multirow{9}{*}{$\begin{array}{l}\text { Economy } \\
\text { (B1) }\end{array}$} & \multirow{3}{*}{$\begin{array}{l}\text { Development } \\
\text { benefit }(\mathrm{C} 1)\end{array}$} & Per-capita disposable income of urban residents & Positive \\
\hline & & & All-personnel labor productivity & Positive \\
\hline & & & Per-capita investment in fixed assets & Positive \\
\hline & & \multirow{3}{*}{$\begin{array}{c}\text { Technical } \\
\text { innovation }(\mathrm{C} 2)\end{array}$} & R\&D expenditure of the whole society as a percentage of GDP & Positive \\
\hline & & & Annual number of patents granted per 10,000 people & Positive \\
\hline & & & Technology market turnover as a percentage of GDP & Positive \\
\hline & & \multirow{3}{*}{$\begin{array}{c}\text { Structural } \\
\text { optimization } \\
\text { (C3) }\end{array}$} & Added value of service industry as a percentage of GDP & Positive \\
\hline & & & Added value of industrial enterprises above the designated size & Positive \\
\hline & & & Total imports and exports as a percentage of GDP & Positive \\
\hline & \multirow{9}{*}{ Society (B2) } & \multirow{3}{*}{$\begin{array}{l}\text { Social structure } \\
\text { (C4) }\end{array}$} & Dual contrast coefficient & Positive \\
\hline & & & Natural population growth rate & Positive \\
\hline & & & Percentage of employees in the tertiary industry & Positive \\
\hline & & \multirow{3}{*}{$\begin{array}{l}\text { Population } \\
\text { quality (C5) }\end{array}$} & Average life expectancy & Positive \\
\hline & & & Number of college students per 10,000 people & Positive \\
\hline & & & Number of professionals per 10,000 people & Positive \\
\hline & & \multirow{3}{*}{$\begin{array}{l}\text { Social order } \\
\quad \text { (C6) }\end{array}$} & Spot check pass rate & Positive \\
\hline & & & Index of law-based government & Positive \\
\hline & & & Deaths per 10,000 traffic accidents & Negative \\
\hline & \multirow{6}{*}{ Ecology (B3) } & \multirow{3}{*}{$\begin{array}{c}\text { Resource } \\
\text { conservation } \\
\text { (C7) }\end{array}$} & Energy consumption per 10,000 yuan of GDP & Negative \\
\hline & & & Water consumption per 10,000 yuan of GDP & Negative \\
\hline & & & Comprehensive utilization rate of general industrial solid waste & Positive \\
\hline & & \multirow{3}{*}{$\begin{array}{l}\text { Environmental } \\
\text { governance } \\
\text { (C8) }\end{array}$} & Centralized treatment rate of sewage treatment plant & Positive \\
\hline & & & Harmless treatment rate of domestic garbage & Positive \\
\hline & & & Percentage of days with good air quality & Positive \\
\hline & \multirow{6}{*}{ Culture (B4) } & \multirow{3}{*}{$\begin{array}{l}\text { Cultural } \\
\text { resources }(\mathrm{C} 9)\end{array}$} & Number of public cultural facilities per 10,000 people & Positive \\
\hline & & & Investment in fixed assets of culture, sports and entertainment & Positive \\
\hline & & & Per-capita public library collections & Positive \\
\hline & & \multirow{3}{*}{$\begin{array}{c}\text { Cultural } \\
\text { industry }(\mathrm{C} 10)\end{array}$} & Added value of culture and related industries as a percentage of GDP & Positive \\
\hline & & & $\begin{array}{c}\text { Expenditure on culture, education and entertainment as a percentage } \\
\text { of total nonproductive expenditure }\end{array}$ & Positive \\
\hline & & & Number of inbound tourists & Positive \\
\hline & \multirow{6}{*}{$\begin{array}{l}\text { Public service } \\
\text { (B5) }\end{array}$} & \multirow{3}{*}{$\begin{array}{c}\text { Social } \\
\text { undertakings } \\
(\mathrm{C} 11)\end{array}$} & Education expenditure as a percentage of GDP & Positive \\
\hline & & & $\begin{array}{l}\text { Social security and employment expenditure as a percentage of } \\
\text { general public budget expenditure }\end{array}$ & Positive \\
\hline & & & Coverage of basic urban endowment and medical insurances & Positive \\
\hline & & \multirow{3}{*}{$\begin{array}{c}\text { Municipal } \\
\text { facilities (C12) }\end{array}$} & Drainage pipe density in built-up area & Positive \\
\hline & & & Per-capita road area & Moderate \\
\hline & & & Green coverage of built-up area & Positive \\
\hline & \multirow{6}{*}{$\begin{array}{c}\text { Urban } \\
\text { management } \\
\text { (B6) }\end{array}$} & \multirow{3}{*}{$\begin{array}{l}\text { Urban-rural } \\
\text { construction } \\
\quad(\mathrm{C} 13)\end{array}$} & Urbanization rate of permanent population & Positive \\
\hline & & & $\begin{array}{l}\text { Per-capita financial expenditure for the construction, maintenance } \\
\text { and management of municipal public facilities }\end{array}$ & Positive \\
\hline & & & Urban construction land as a percentage of urban area & Positive \\
\hline & & \multirow{3}{*}{$\begin{array}{c}\text { Sustainable } \\
\text { development } \\
\text { (C14) }\end{array}$} & IT and telecom infrastructure index & Positive \\
\hline & & & Number of international navigable cities & Positive \\
\hline & & & Urban operating rate & Positive \\
\hline
\end{tabular}

The quality of economic development reflects the economic potential of the region. It is manifested as the sharing of development benefit, ability of technical innovation, and coordination of structural optimization Therefore, three secondary indices were designed for the economy criterion of urban development quality: development benefit, technical innovation and structural optimization. Among them, development benefit contains three tertiary indices: per-capita disposable income of urban residents, all-personnel labor productivity, and per-capita investment in fixed assets; technical innovation covers three tertiary indices: R\&D expenditure of the whole society as a percentage of GDP, annual number of patents granted per 10,000 people, and technology market turnover as a percentage of GDP; structural optimization also involves three tertiary indices: added value of service industry as a percentage of GDP, added value of industrial enterprises above the designated size, and total imports and exports as a percentage of GDP. To improve quality and benefits of urban economic growth, the economy criterion aims to forge an innovation-friendly market and promote the upgrading of industrial structure by deepening the structural reform and advancing innovation-driven development.

The quality of social development mirrors how the key elements of the social system grow and evolve with the society, and how these elements coordinate and coexist with each other in an orderly manner. To assess the overall social development of the region, three secondary indices were designed for the society criterion: social structure, population quality and social order. Among them, social structure contains three tertiary indices: dual contrast coefficient, natural population growth rate, and percentage of employees in the tertiary industry; population quality involves three tertiary indices: average life expectancy, number of college students per 10,000 people, and number of professionals per 10,000 people; social order also covers three tertiary indices: spot check pass rate, index of 
law-based government, and deaths per 10,000 traffic accidents. Overall, the society criterion aims to broaden the space, strengthen the order and improve the quality of urban development, through regional coordination and structural optimization.

The quality of ecological development describes how much the factors of ecological system, alone or combined, suit human survival and sustainability of social economy in a specific time and space. Hence, two secondary indices were selected for the ecology criterion: resource conservation and environmental governance. Among them, resource conservation has three tertiary indices: energy consumption per 10,000 yuan of GDP, water consumption per 10,000 yuan of GDP, and comprehensive utilization rate of general industrial solid waste; environmental governance also has three tertiary indices: centralized treatment rate of sewage treatment plant, harmless treatment rate of domestic garbage, and percentage of days with good air quality. In the principle of green development, the ecology criterion attempts to build environmental-friendly cities by promoting intensive use and recycling of resources, strengthening environmental governance and resolving overcapacity.

The quality of cultural development refers to the abilities of a city to attract cultural resources, meet the spiritual needs of its residents, and make a profit out of cultural resources. Here, two secondary indices were chosen for the culture criterion: cultural resources and cultural industry. Among them, cultural resources include three tertiary indices: number of public cultural facilities per 10,000 people, investment in fixed assets of culture, sports and entertainment, and per-capita public library collections; cultural industry also contains three tertiary indices: added value of culture and related industries as a percentage of GDP, expenditure on culture, education and entertainment as a percentage of total nonproductive expenditure, and number of inbound tourists.

The quality of public service manifests how well the administrative subject utilizes public resources, rights and funds to implement social undertakings and build municipal facilities. The authors designed two secondary indices under the criterion of public service: social undertakings and municipal facilities. Among them, social undertakings contain three tertiary indices, namely, education expenditure as a percentage of GDP, social security and employment expenditure as a percentage of general public budget expenditure, and coverage of basic urban endowment and medical insurances. Meanwhile, municipal facilities also involve three tertiary indices, i.e. drainage pipe density in built-up area, per-capita road area, and green coverage of builtup area. To realize coordinated and shared development, the public service criterion strives to build better municipal facilities that ensure the supply of public services, optimize the spatial layout of cities, step up financial investment and cost control, and promote the equity of social security.

The quality of urban management refers to the effects of policies, coordination, services and operations on urban-rural construction and sustainable development. Here, two secondary indices are arranged under the criterion of urban management: urban-rural construction and sustainable development. Among them, urban-rural construction has three tertiary indices: urbanization rate of permanent population, per-capita financial expenditure for the construction, maintenance and management of municipal public facilities, and urban construction land as a percentage of urban area; sustainable development also encompasses three tertiary indices: IT and telecom infrastructure index, number of international navigable cities, and urban operating rate. Highlighting innovation, coordination and openness, the criterion of urban management focuses on the overall planning of cities, urban-rural integration, and sustainability of urban development.

\subsection{Data sources}

The research objects are the fifteen sub-provincial cities in China, namely, Guangzhou, Wuhan, Harbin, Shenyang, Chengdu, Nanjing, Xi'an, Changchun, Jinan, Hangzhou, Dalian, Qingdao, Shenzhen, Xiamen and Ningbo. The relevant data were collected from China Statistical Yearbook 2017, China City Statistical Yearbook 2017, China Statistical Yearbook for Regional Economy 2017, Statistical Bulletin on National Economic and Social Development 2017, Communiqué on Major Figures of the 2010 Population Census, as well as the statistical yearbooks issued by the fifteen cities in 2017. The missing data were interpolated by means and hierarchical means, or replaced with the data in adjacent years.

\subsection{Evaluation method}

The quality of urban development depends on the values of multiple indices. To compare the urban development qualities of different cities, the development quality score of each city should be calculated based on multiple indices in the index system. Here, the AHP is adopted to assign a weight to each index, and the WSM is employed to compute the criterion scores and total score of each city.

(1) Index weight

The weight of each evaluation index was determined by the AHP, a popular weighting method for multi-factor comprehensive evaluations. During the AHP, the importance of each index is rated by experts and decision makers through pairwise comparison; the contribution of an index to its superior index is obtained by computing the eigenvectors of judgment, revealing the importance of each alternative to the goal. The AHP is a simple and clear way to measure the actual quality of urban development. The AHP-based index weighting is implemented in the following steps:

Step 1. AHP model

As shown in Table 1, the model includes the goal layer, the criteria layer and the alternatives layer.

Step 2. Pair wise comparison matrices

The importance of each index relative to its superior index was evaluated through pair wise comparison, rated against a 1-9 scale, and added to a pair wise comparison matrix. Suppose $x_{i}$ and $x_{j}$ are selected for comparison. Let all be the ratio of their impacts on the goal. Then, the pair wise comparison matrix can be expressed as: $A=\left(a_{i j}\right) n \times n$.

Step 3. Consistency tests

The maximum value of each pair wise comparison matrix, and its corresponding eigenvector, were calculated, and subjected to consistency tests, using consistency index (CI) and consistency ratio $(\mathrm{CR})$ :

$$
\begin{aligned}
& C I=\frac{\lambda_{\max }-n}{n-1}, \\
& C R=\frac{a_{1} C I_{1}+a_{2} C I_{2}+\ldots+a_{m} C I_{m}}{n a_{1} R I_{1}+n a_{2} R I_{2}+\ldots+n a_{m} R I_{m}-1}, \\
& C R \leq 0.1
\end{aligned}
$$


If the results pass the tests, the eigenvector will be normalized into the weight vector; otherwise, the pair wise comparison matrix will be reconstructed. If CR is smaller than 0.1 , the pair wise comparison matrix is acceptably consistent; otherwise, the matrix should be revised until passing the tests.

Step 4. Weight vectors

After passing the consistency tests, the weight vector of each index was computed by normalizing the eigenvector.

(2) Normalization

The original data were normalized to eliminate the differences in dimension, order of magnitude and positivity/negativity. The positive indices, negative indices and moderate index were respectively normalized by:

$$
\begin{gathered}
x_{i}=\frac{y_{i}-y_{\text {min }}^{i}}{y_{\text {max }}^{i}-y_{\text {min }}^{i}} \times \alpha+\beta-\alpha \\
x_{i}=\frac{y_{\text {max }}^{i}-y_{i}}{y_{\text {max }}^{i}-y_{\text {min }}^{i}} \times \alpha+\beta-\alpha \\
x_{i}=\beta+\alpha-\frac{\left|y_{i}-y_{0}\right|}{y_{0}} \times \alpha
\end{gathered}
$$

(3) Criterion score and total score

The total score Fi of sub-provincial city i can be computed by the WSM:

$$
F_{i}=\sum_{i=1}^{6} \lambda_{j} x_{i j}(i=1,2,3, \ldots, 6 ; \mathrm{j}=1,2,3, \ldots, 42)
$$

\section{RESULTS ANALYSIS}

The total score and criterion scores of each sub-provincial city are presented in Table 2 and Figure 2.

\subsection{Score analysis}

As shown in Figure 2, Shenzhen achieved the highest total score of urban development quality, followed in turn by Guangzhou, Xiamen, Nanjing and Hangzhou. Harbin, Changchun and Shenyang came at the bottom of the total score ranking. There are huge gaps between the top two cities, and between the bottom two cities. Except for these two pairs, there are no obvious gaps in total score between adjacent cities.

Table 2. The total and criterion scores of sub-provincial cities

\begin{tabular}{cccccccc}
\hline & Economy & Society & Ecology & Culture & Public service & Urban management & Total score \\
\hline Shenzhen & 0.3621 & 0.2664 & 0.2692 & 0.3636 & 0.2165 & 0.3434 & 0.5654 \\
Guangzhou & 0.2761 & 0.2265 & 0.24 & 0.3236 & 0.2555 & 0.2915 & 0.4729 \\
Xiamen & 0.2495 & 0.2361 & 0.2786 & 0.2113 & 0.2026 & 0.3715 & 0.4561 \\
Nanjing & 0.1516 & 0.2824 & 0.2671 & 0.166 & 0.2397 & 0.135 & 0.446 \\
Hangzhou & 0.2669 & 0.1913 & 0.2599 & 0.2823 & 0.277 & 0.2403 & 0.4358 \\
Xi'an & 0.2543 & 0.2674 & 0.2306 & 0.2179 & 0.2271 & 0.1971 & 0.4212 \\
Ningbo & 0.2524 & 0.1896 & 0.2676 & 0.2259 & 0.2843 & 0.2218 & 0.4109 \\
Chengdu & 0.2157 & 0.2342 & 0.2461 & 0.2305 & 0.2062 & 0.2633 & 0.4058 \\
Jinan & 0.2155 & 0.2264 & 0.2557 & 0.1667 & 0.1893 & 0.2024 & 0.404 \\
Qingdao & 0.2199 & 0.1822 & 0.2242 & 0.1538 & 0.2149 & 0.2083 & 0.4028 \\
Dalian & 0.1971 & 0.1948 & 0.2706 & 0.1829 & 0.2842 & 0.1737 & 0.4006 \\
Wuhan & 0.2466 & 0.2552 & 0.2568 & 0.2518 & 0.2653 & 0.2171 & 0.3974 \\
Harbin & 0.2612 & 0.208 & 0.2398 & 0.231 & 0.2787 & 0.2491 & 0.3826 \\
Changchun & 0.1778 & 0.1887 & 0.261 & 0.2299 & 0.1745 & 0.152 & 0.3706 \\
Shenyang & 0.1228 & 0.1626 & 0.2483 & 0.1518 & 0.2104 & 0.2159 & 0.2861 \\
\hline
\end{tabular}

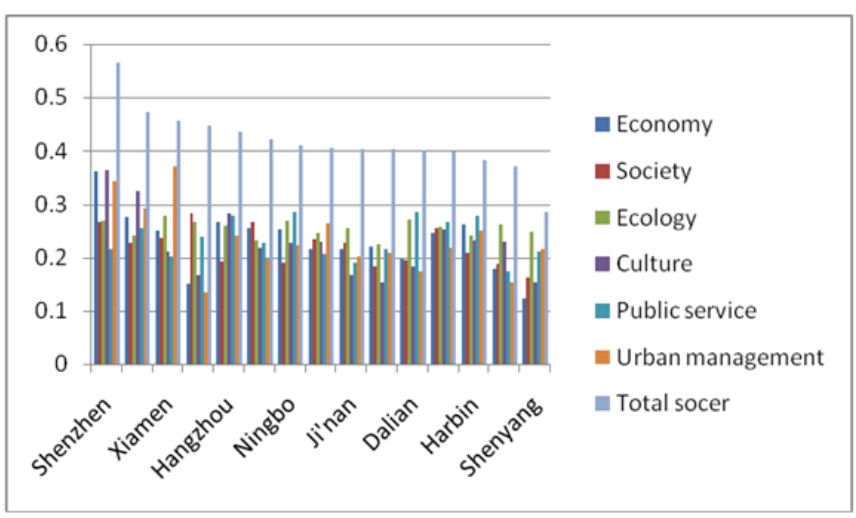

Figure 2. The total and criterion scores of sub-provincial cities

In terms of criterion scores, Shenzhen scored the highest in economy, culture and urban management; the highest scores in society, ecology and public service went to Nanjing, Xiamen, and Ningbo, respectively.

\subsection{Feature analysis}

(1) The quality of urban development shows obvious regional differences. In general, the cities in the eastern region are more developed than those in the central and western regions, and the cities in the southern region are more developed than those in the northern region. The cities in developed areas boast relatively high development quality, because city clusters are relatively mature in these areas.

By contrast, northeastern cities like Shenyang, Changchun and Harbin have relatively low development quality, due to the slow social and economic development in the region. This means the development quality of a city depends on the social economy of the region and its interaction with other cities in that region, in addition to its own efforts.

(2) Large cities are not necessarily better developed. Taking the population of municipal districts as the size of each city, the top two sub-provincial cities in development quality are ultra-megacities: Shenzhen and Guangzhou.

However, megacities like Wuhan, Harbin and Shenyang rank lower than large cities like Ningbo and Qingdao. Hence, 
there is no absolutely positive correlation between city size and development quality.

(3) To realize high-quality development, a city must strike a balance between multiple aspects, such as economy, society, ecology, public service and urban management. There should be no aspect that is significantly weaker than others. On this basis, the city will attain a good development quality, if it excels in several aspects.

For instance, Shenzhen, Guangzhou and Xiamen occupy the top of the ranking of total score, for each of them ranks among the top in at least four aspects.

(4) There are marked differences between the subprovincial cities in culture and urban management, according to standard deviations and coefficient variations.

Therefore, the target cities should further improve the development quality in the two aspects. To make a breakthrough in development quality, the cities ought to focus their energy in culture and urban management.

\section{CONCLUSIONS}

Based on the connotations of urban development quality in the new era, this paper sets up a $1+2+3+4+5+6$ logical framework and then establishes an evaluation index system for urban development quality in the new era. Next, the AHP and WSM were introduced to evaluate the development quality of the 15 sub-provincial cities in China. The main conclusions are as follows:

(1) In terms of development quality, the sub-provincial cities are ranked in descending order as: Shenzhen, Guangzhou, Xiamen, Nanjing, Hangzhou, Xi'an, Ningbo, Chengdu, Jinan, Qingdao, Dalian, Wuhan, Harbin, Changchun and Shenyang. There are huge gaps between the top two cities, and between the bottom two cities.

(2) The quality of urban development shows obvious regional differences. In general, the cities in the eastern region are more developed than those in the central and western regions, and the cities in the southern region are more developed than those in the northern region. The cities in western, central and northeastern regions should learn from those in southeast coastal areas to improve their development quality.

(3) Large cities are not necessarily better developed. Taking the population of municipal districts as the size of each city, many smaller cities are better developed than larger cities. This means the cities should select a development mode suitable for the local conditions. The urban development must be people-oriented: serving production and life instead of pursuing a larger size.

(4) The different aspects of urban development should be more balanced. Currently, many cities have not paid enough attention to some of the aspects. In future, the under-invested aspects should be highlighted to realize overall improvement of development quality.

(5) There are marked differences between the subprovincial cities in culture and urban management. The cities that perform poorly in the two aspects should improve culture and urban management, in the light of their own features.

\section{ACKNOWLEDGMENT}

This work is supported by Natural Science Foundation of
Zhejiang Province (Grant No.: LQ18G030001, LY18G030001 and LY19G03002), Natural Science Foundation of Ningbo (Grant No.: 2019A10036), Famous Teachers' Studio Project of Ideological and Political Theory Course in Colleges and Universities of Zhejiang Province and Philosophy and Social Sciences Plan of Ningbo (Grant No.: G20-ZX61).

\section{REFERENCES}

[1] Wang, D.L., Fang, C.L., Yang, Q.S. (2010). Judgment and analysis of urbanization development speed in china based on urbanization quality. Geographica Science, 30(5): 643-650. http://doi.org/CNKI:SUN:DLKX.0.2010-05-003

[2] May, R. (2001). UNCHS Reports the state of the World's Cities, and Cities in A Globalizing World: Presented at Istanbul+5 (June 2001), 19(1): 79-80. http://doi.org/10.1016/s0264-2751(01)00047-6

[3] Rodrigues da Silva, A.N. (2015). Proceedings of the institution of civil engineers - urban design and planning. book review: united nations human settlements programme (UN-Habitat). Planning and Design for Sustainable Urban Mobility, 167(4): 185-185. http://doi.org/10.1680/udap.14.00009

[4] Elkington, J. (1998). Partnerships from cannibals with forks: The triple bottom line of 21 st-century business. Environment Quality Management, 8(1): 37-51. http://doi.org/10.1002/tqem.3310080106

[5] Midgley, G., Reynolds, M. (2004). Systems/operational research and sustainable development: Towards a new agenda. Sustainable Development, 12(1): 56-64. http://doi.org/10.1002/sd.218

[6] Schoolman, E.D., Guest, J.S., Bush, K.F., Bell, A.R. (2012). How interdisciplinary is sustainability research? Analyzing the structure of an emerging scientific field. Sustainability $\quad$ Science, 7(1): 67-80. http://doi.org/10.1007/s11625-011-0139-Z

[7] Zijp, M.C., Heijungs, R., Van der Voet, E., Van de Meent, D., Huijbregts, M.A., Hollander, A., Posthuma, L. (2015). An identification key for selecting methods for sustainability assessments. Sustainability, 7(3): 24902512. https://doi.org/10.3390/su7032490

[8] Boyer, R.H., Peterson, N.D., Arora, P., Caldwell, K. (2016). Five approaches to social sustainability and an integrated way forward. Sustainability, 8(9): 878. https://doi.org/10.3390/su8090878

[9] Arushanyan, Y., Ekener, E., Moberg, Å. (2017). Sustainability assessment framework for scenariosSAFS. Environmental Impact Assessment Review, 63: 23-34. https://doi.org/10.1016/j.eiar.2016.11.001

[10] Wang, S.H., Mao, C.S. (2018). Evaluation of regional manufacturing quality competitiveness based on analytic network. Journal Européen des Systemes Automatisés, 51(1-3): 109-124. http://doi.org/10.3166/JESA.51.109124

[11] Feleki, E., Vlachokostas, C., Moussiopoulos, N. (2018). Characterisation of sustainability in urban areas: An analysis of assessment tools with emphasis on European cities. Sustainable Cities and Society, 43: 563-577. https://doi.org/10.1016/j.scs.2018.08.025

[12] Cloke, P.J. (1977). An index of rurality for England and Wales. Regional Studies, 11(1): 31-46. 
http://doi.org/10.1080/09595237700185041

[13] Yang J.Y., Chen W., (2010). Research on the evaluation model of the modernization level of urban construction in Jiangsu Province, Chin. Science China, (9): 204-208. http://doi.org/10.1007/s11431-010-4026-0

[14] Ye, Y.M. (2001). Approach on China's urbanization quality. China Soft Science, 7: 27-31. http://doi.org/10.3969/j.issn.1002-9753.2001.07.006

[15] Porter, M.E. (2011). Competitive advantage of nations: creating and sustaining superior performance. Simon and Schuster, ISBN: 0-684-84147-9.

[16] Rondinelli, D.A. (1990). Housing the urban poor in developing countries: The magnitude of housing deficiencies and the failure of conventional strategies are world-wide problems. American Journal of Economics and Sociology, 49(2): 153-166. http://doi.org/10.2307/3487429

[17] Kresl, P.K., Singh, B. (1999). Competitiveness and the urban economy: Twenty-four large US metropolitan areas. Urban Studies, 36(5-6): 1017-1027. http://doi.org/10.1080/0042098993330

[18] IMD International (Institute). (2014). IMD World Competitiveness Yearbook.

[19] Ni, P.F. (2001). China Urban Competitiveness: theoretical hypothesis and empirical test. Beijing: Economic Press China, (1): 21-24. http://doi.org/10.3969/j.issn.1005-278X.2001.01.003

[20] Ni, P.F. (2005). Annual report on urban competitiveness. Social Sciences Academic Press, Beijing.

[21] Voelkel, J.G. (1989). Guide to quality control. $\begin{array}{lll}\text { Technometrics, } & 31(2) \text { : } & 260 .\end{array}$ http://doi.org/10.1080/00401706.1989.10488523

[22] Bossert, J.L. (1992). Introduction to quality control. Technometrics, 34(4): http://doi.org/10.1080/00401706.1992.10484970 